\title{
The active Dead Sea Rift fault zone: a seismic wave-guide
}

\author{
G. H. Wust-Bloch \\ Department of Geophysics and Planetary Sciences, Tel Aviv University, Tel Aviv, Israel (Email: hillel@ seismo.tau.ac.il)
}

Received: 3 January 2001 - Revised: 3 December 2001 - Accepted: 29 January 2002

\begin{abstract}
The analysis of several types of earthquakeinduced failure features in the Dead Sea Rift (DSR) region reveals peculiarities that depart from habitual damage distribution patterns observed elsewhere. These observations, together with a series of unusual seismic characteristics, suggest that the structure of the DSR influences the dissipation of seismic energy and acts as a wave-guide.

First, this paper describes both a series of ancient failure features that were seismically triggered as well as the behavior of several recent earthquakes. The paper then reviews the large-scale tectonic structure of the DSR through geophysical surveys in order to predict its potential effect on seismic energy dissipation. Finally the wave-guide work hypothesis is verified based on the results of recent seismological investigations carried out independently around the DSR fault zone. The conclusion of this work discusses some of the implications of this special filtering effect for seismic hazard assessment and suggests directions for further research.
\end{abstract}

Key words. Dead Sea Rift, active fault zone, seismic waveguiding, earthquake-induced failure features, seismic load evolution

\section{Introduction}

Investigations of seismically-induced paleolandslides have shown that a number of earthquakes have triggered instabilities at epicentral distances that exceed worldwide observations (Wust-Bloch and Wachs, 2000). A survey of archeological structures shows a very selective destruction pattern whereby every site located within the Dead Sea Rift (DSR) reveals signs of destruction while structures located a few kilometers away from the DSR are still intact after 2000 years (Wust-Bloch, 2000). In the DSR region, instrumental records also demonstrate that earthquakes are capable of triggering sensors at unusual distances. The Jericho earthquake of 11 July $1927\left(m_{b} 6.25\right)$, was recorded by a station located about $700 \mathrm{~km}$ away from the epicenter (Shapira et al., 1993). Similarly, the moderate 2 September 1973, Kinneret earthquake $(M 4.5)$ was felt in the Negev, more than
$200 \mathrm{~km}$ away (Arieh et al., 1977). During the 22 November 1995, Nuweiba earthquake $\left(M_{b} 6.25\right)$, Peak Ground Accelerations (PGA) recorded more than $500 \mathrm{~km}$ from the epicenter (Shamir, 1996; Shapira et Shamir, 1996) were unexpectedly high, not to mention unexpected failures of elevators in buildings located hundreds of kilometers from the epicenter (Levy et al., 2000).

These seismographic records, as well as numerous seismically-induced failure features, are perfectly consistent with a series of recent seismic observations at different scales. At a regional scale, $S_{n}$ and $P_{g}$ waves are reported to be filtered in the vicinity of the DSR (Rodgers et al., 1997). At a local scale, a monitoring array deployed in the Negev (Bartal et al., 2000), received microseisms located in the DSR faster than expected based on predictions using a direct path. These observations confirm previous coda wave studies showing a discrepancy between the DSR and the flank of the rift (van Eck, 1988).

The results of this series of independent investigations suggest that the peculiar structure of the DSR significantly filters seismic loads. It can be seen that both at a regional and at a local scale, the DSR acts as a wave-guide. The special structure of the DSR with its simple geometry and extremely sharp lithological contrasts will, in certain cases, allow for the trapping of seismic loads and their displacement over large distances with minimal energy losses.

Numerical simulations of the seismic load filtering by the DSR are urgently required for such vital tasks as the assessment of seismic hazard in the DSR region or the global monitoring of seismic activity within the framework of the Comprehensive Test Ban Treaty (CTBT).

\section{Observations in the DSR region}

In the DSR region, a series of earthquake-triggered failure features have been observed in landslides, in archeological structures as well as in elevators. Their analysis, together with instrumental data from recent earthquakes, suggests that the dispersion pattern of seismic energy is unusual and might be influenced by the DSR substructure. 


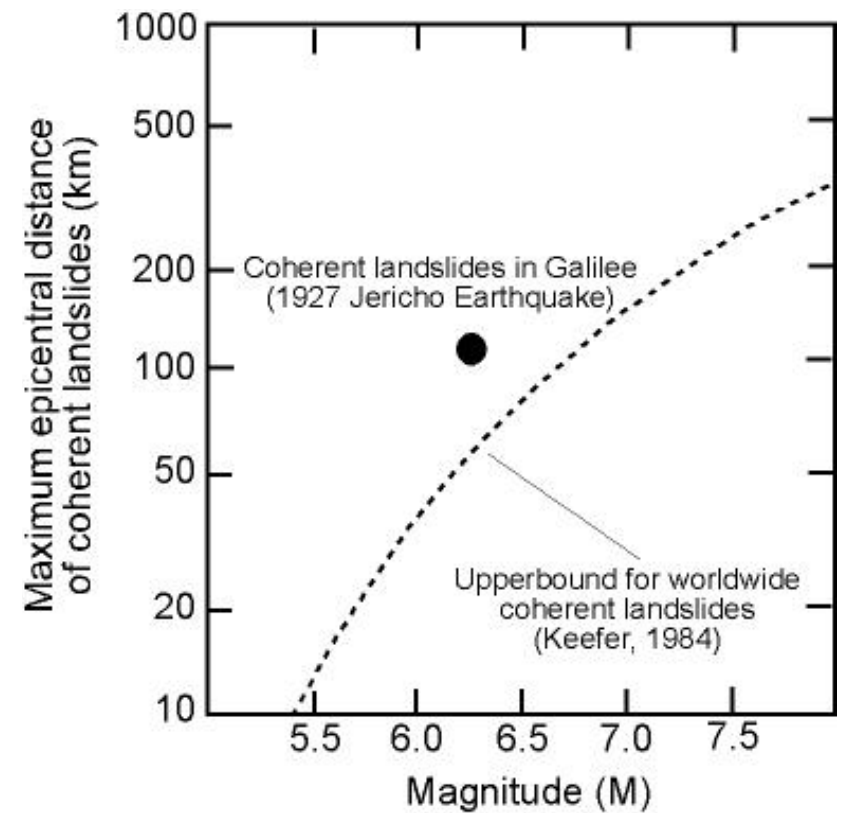

Fig. 1. Maximal epicentral distance from the 11 July 1297 Jericho earthquake $\left(M_{b} 6.25\right)$ epicenter to coherent landslides in the Galilee (modified after Keefer, 1984). The dashed line is the upperbound for worldwide coherent landslides given by Keefer (1984).

\subsection{Landslides}

Since ancient times, Northern Israel, part of which lies within the DSR, has been known for its high landslide hazard. The high clay and marl content of the regional lithologies, the steepness of the slopes together with the abundant seasonal rainfall have been documented in a variety of investigations (Wiseman et al., 1970; Wachs and Levitte, 1978, 1980, 1981) and held to be the cause of slope instabilities in the region. Wachs and Levitte $(1978,1980,1981)$ noted the repeated failure of slopes, mostly shallow colluvium masses, in direct relation with peak rainfall events. However, the monitoring of unstable slopes in Northern Israel (Wust and Wachs, 1996, 1998a; Wust et al., 1997) has revealed that over a period of 36 months, no direct relationship was found between seasonal variations of the groundwater table and the average downhill displacement (10-30 mm/year) of the landslide (Wust et al., 1997; Wust-Bloch and Wachs, 2000). The slopes, which are characterized by low residual strength and fail at random intervals in time and space, independently of the fluctuation of their groundwater tables, are extremely sensitive to additional seismic loads (Wachs and Wust, 1998; Wust and Wachs, 1998b; Wust-Bloch and Wachs, 2000). Indeed, several instances of earthquake triggered slope instabilities have been reported either around Jerusalem (Wachs and Lewitte, 1984) or in the Galilee region (Wachs and Levitte, 1978, 1980, 1981). Niemi and Ben-Avraham (1994, 1997) even documented a case of underwater sediment slumping triggered by an earthquake in the Dead Sea.

The analysis of the most recent strong earthquake, the 11 July 1927 Jericho earthquake $\left(M_{b} 6.25\right)$, shows that its effect on slope stability was unusual in many aspects (WustBloch and Wachs, 2000). Slope failures were responsible for most of the death toll and structural damage, particularly in the city of Nablus (Vered and Striem, 1976a, 1976b, 1977). Taking place during the driest time of the year, it triggered deep, large-scale landslides in addition to the usual shallow colluvium failures. More surprisingly, it triggered slope failure at epicentral distances that depart from and significantly exceed data collected worldwide for landslides induced by earthquakes (Keefer, 1984; Fig. 1). The upper boundary given by Keefer (1984), limits a cluster of landslide data collected from 19 earthquakes that have triggered coherent landslides in similar lithologies. In the DSR region, destructive coherent slope failures have occurred in the village of Reineh, more than $120 \mathrm{~km}$ away form the epicenter (WustBloch and Wachs, 2000). Since, the material and landslide type of this site do not even qualify as belonging to one of the ten most failure-prone environments proposed by Keefer (1984), an additional factor that contributes to the instability must be involved.

\subsection{Archeological structures}

The DSR region encompasses an extremely high number of archeological sites reaching back well over 2000 years into the Hellenistic period. A series of comprehensive paeloseismological investigations have been carried out on selected sites near or on the active DSR fault zone (Ellenblum et al., 1998; Marco et Agnon, 1995; Marco et al., 1996, 2000; Nur and Ron, 1997). In specific instances, these analyses of earthquake-induced structural failures provided a quantitative assessment of paelo-displacement that was then related to the magnitude of ancient earthquakes (Ellenblum et al., 1998; Marco et al., 2000). Together with an exceptional archeological and historical record, the fact that relatively few strong earthquakes shook Northern Israel over the life-time of the structures enables to know which event(s) affected a given structure. In addition, for repeated events, Marco et al. (2000) have shown that meticulous paleoseismological investigations and archeological evidences generally permit to identify which structural damage was caused by which event. Thus, the high density and rather homogeneous distribution of ancient structures that have sustained or suffered from a series of strong earthquakes in the region (Amiran et al. 1995) can be used to map failures induced by paeloseisms. Sites were mapped as having failed when field evidences (Ellenblum et al., 1998; Marco et al., 1996, 2000; Nur and Ron, 1997; Stern et al., 1993; comm. pers. Moti Aviam) showed that its structure was directly displaced, shared or destroyed either by strong ground motion or by surface rupture. Sites were mapped as not having been structurally affected by ground motion when its supporting structure remained intact at its original height till this day (Stern et al., 1993; comm. pers. Moti Aviam). Special care was taken to exclude bias from sites that had been renovated or even partly supported as well as those for which data was not reliable (comm. pers. Moti Aviam). The plotting (Fig. 2) 


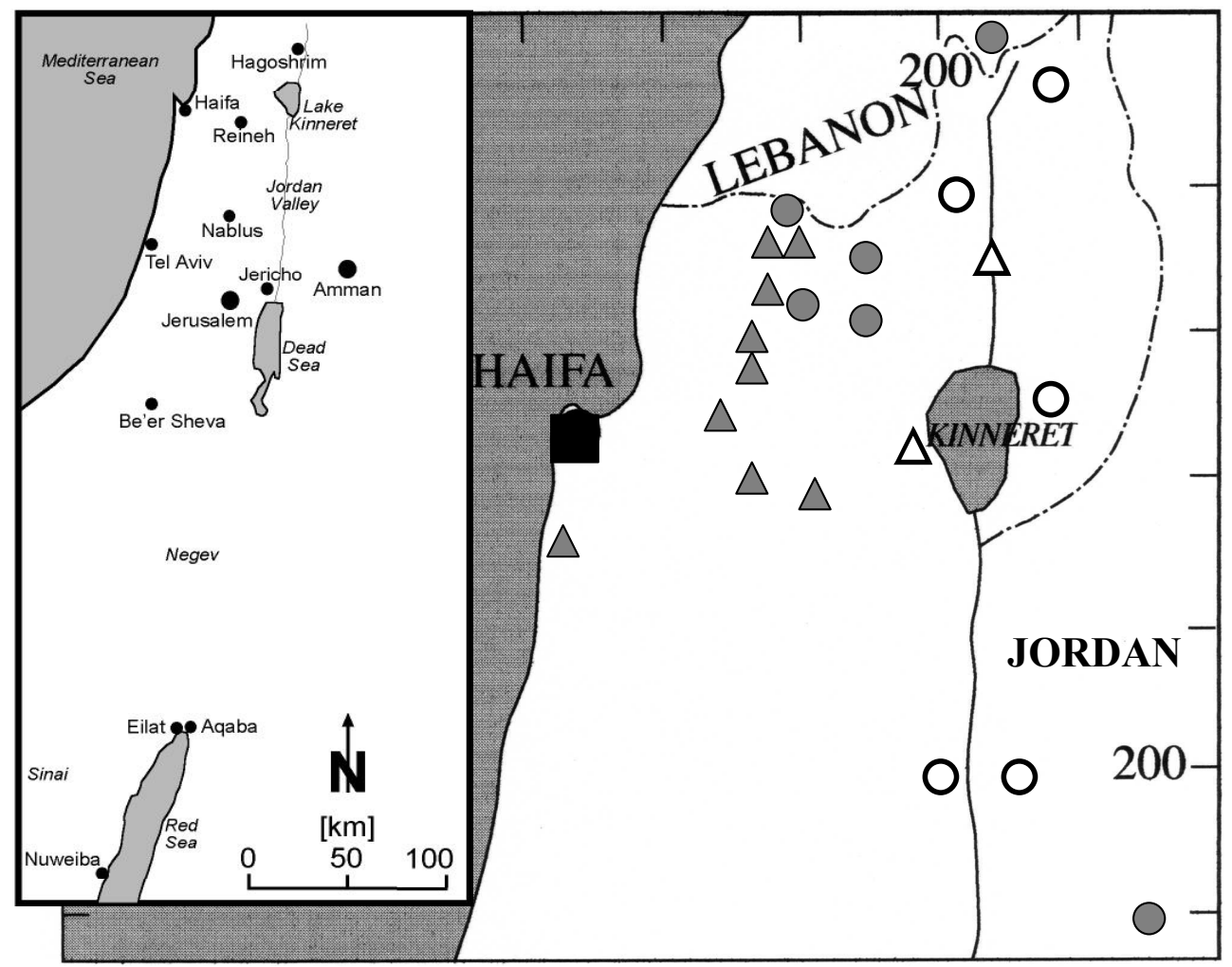

Fig. 2. Location map of the DSR region and map of Northern Israel showing the selective distribution of archeological structures that failed (open symbols) and that are still intact (plain symbols) as a result of earthquakes. Circles mark structures that were built during Roman time ( $<1800$ years), Triangles locate structures that were built during the Crusaders Period ( $<800$ years).

of two-dozen archeological structures on a map shows a selective distribution of failure (Wust-Bloch, 2000), which singularly differs from the expected pattern of destruction that would gradually fade away from the DSR seismogenic zone as a function of distance. First, a series of seven sites that present earthquake-induced structural failure, are all located exclusively within or on the DSR fault zone. Second, structures, some of them dating back 2000 years, located only a few kilometers away from the DSR fault zone, on the shoulders of either side of the DSR, are still structurally intact today. In addition, a significant number of intact archeological structures have also been reported to exist further North of the DSR, in the Bakaa Valley (Lebanon).

While the systematic failure of ancient structures along the active DSR fault zone is no surprise, this sharply contrasts with the presence of intact archeological structures on both sides and so near the active fault zone. Such a distribution pattern of paelofailures suggests either a very strong attenuation of seismic loads in a direction normal to the DSR, or a very strong amplification along the DSR axis. Since these ancient structures, including those in the DSR, all sustained several strong earthquakes and were built in commanding positions directly on the bedrock, their selective spatial distribution indicates a recurring anisotropic dispersion of seismic loads within and around the DSR rather than either anomalies due to site effects or to the particularities of individual seismic events.

\subsection{Elevators}

Among modern structures, an elevator that works as an inverse pendulum can provide semi-quantitative data on the ground accelerations withstood by structures (Segal et al., 1996). The performance of elevator systems in Israel was examined after the 22 November 1995, Nuweiba earthquake $\left(M_{b}\right.$ 6.25) (Levy et al., 2000). The study revealed that elevator failure was not limited to the city of Eilat, located at an epicentral distance of about $90 \mathrm{~km}$ to the North of Nuweiba (Sinai, Egypt), but extended to Be'er Sheva in the Negev $(280 \mathrm{~km})$ and to the Dead Sea region $(300 \mathrm{~km})$, as well as to the Central region of Tel Aviv $(350 \mathrm{~km})$. Unfortunately, the high number and diversity of parameters responsible for elevator failure prevents an accurate quantification of the ground motion. In addition, since very few structures have elevators and no data is available for the DSR region stretching between the Dead Sea and the lake Kinneret, the spatial distribution of lift failure is biased. Besides indicating that the present standards are inadequate (Levy et al., 2000), the unexpected extent of elevator failure triggered by this moderate earthquake at epicentral distances exceeding $350 \mathrm{~km}$ suggests, again, that the high level of ground motion observed results from the fact that the dispersion of seismic energy is facilitated along the $\mathrm{N}-\mathrm{S}$ axis. 


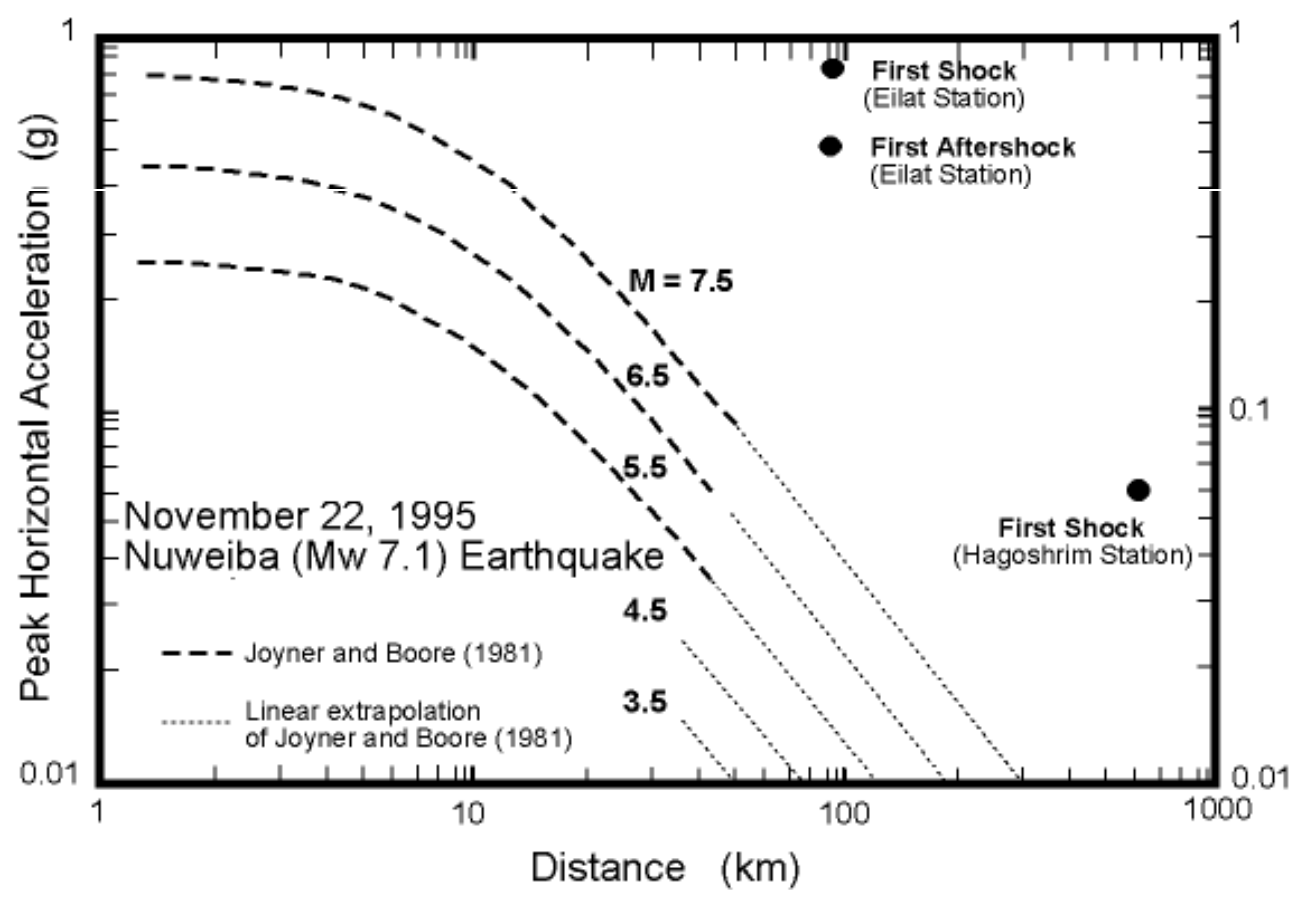

Fig. 3. Synthesis of median (50th percentile) estimates for peak horizontal acceleration (PGA) as predicted by Joyner and Boore (1981) (modified after Reiter, 1990). The data of the 22 November 1995, Nuweiba Earthquake $\left(M_{b} 6.25, M_{w} 7.1\right)$ significantly exceeds ground motion predictions, for the main shock and for the first aftershock at stations located at 93 and at $502 \mathrm{~km}$ from the epicenter.

\subsection{Ground motion}

A series of recent earthquakes, some of them at very low magnitudes, were felt and recorded at unusually large epicentral distances. The epicenter of the 2 September 1973, Kinneret earthquake ( $M$ 4.5) was located in the southeastern part of the lake Kinneret (Amiran et al. 1995). This weak seism was felt (MMS III-IV) all the way down to the Negev region at epicentral distances exceeding $180 \mathrm{~km}$ (Arieh et al., 1977). The 22 November 1995, Nuweiba Earthquake $\left(M_{b} 6.25\right.$, $M_{w}$ 7.1) was recorded by at least nine stations of the national seismic monitoring network operated by the Geophysical Institute of Israel (Shamir, 1996; Shapira et Shamir, 1996). The Eilat station, located $93 \mathrm{~km}$ from the epicenter, recorded peak horizontal ground accelerations (PGA) of (E-W) 91.1 or $(\mathrm{N}-\mathrm{S}) 79.0 \mathrm{~cm} / \mathrm{s}^{2}$ for the first shock and $(\mathrm{E}-\mathrm{W}) 42.1$ or $(\mathrm{N}-\mathrm{S}) 36.1 \mathrm{~cm} / \mathrm{s}^{2}$ for the first aftershock. Even more striking is the fact that at an epicentral distance of $502 \mathrm{~km}$, the Hagoshrim station recorded horizontal PGA of (E-W) 5.1 to (N-S) $4.4 \mathrm{~cm} / \mathrm{s}^{2}$.

Within the framework of the seismic exclusion zone design, a tripartite microseismic array picked up the 9 October 1998, Dead Sea earthquake, which had a very low magnitude $\left(M_{L} 2.1\right)$ at a hypocentral distance of $81.5 \mathrm{~km}$ (Bartal et al., 2000).

The unusual level of ground motion in the region is best understood when compared to available empirical attenuation relations. Based on relations proposed by Joyner and Boore (1981) for strong motion records for up to $400 \mathrm{~km}$, Reiter (1990) designed a comprehensive diagram of median (50th percentile) estimates for peak horizontal acceleration. When plotted (Fig. 3) in a modified version of Reiter's (1990) diagram (increased distance axis and without curves for distances up to $50 \mathrm{~km}$ proposed by Campbell, 1981), the data of the 22 November 1995, Nuweiba Earthquake $\left(M_{b} 6.25\right.$, $\left.M_{w} 7.1\right)$ significantly exceeds ground motion predictions, for both the main shock as well as for the first aftershock at stations located at 93 and at $502 \mathrm{~km}$ from the epicenter. Since the smallest magnitude considered by both Campbell (1981) and Joyner and Boore (1981) is 5.5, lower magnitude observations ( $M 4.5$ and $M_{L} 2.1$ ) cannot be compared directly. However a simple linear extrapolation of the relation proposed by Joyner and Boore (1981) suggests that events of a magnitude lower than 5.5 should not be recorded beyond about $100 \mathrm{~km}$, a fact that contradicts a series of ground motion observations of small magnitude events.

Even if the unexpectedly high PGA level of some sites, such as the Eilat station, might have resulted from the amplification of on-coming low frequency events in the granular soil (Levy et al., 2000), significant site effects are not expected for the majority of observations. In fact, the data from the 1988 Dead Sea (M 2.1) and 1973 Kinneret (M 4.5) earthquakes as well as most of the data for the 1995 Nuweiba earthquake $\left(M_{b} 6.25\right)$ was recorded in stations for which neither the nature of the soil nor the presence of disturbing geomorphologic features such as alluvial fans and playa, can be invoked. Furthermore, the fact that $P$ - and $S$-phase arrivals seem to be mixed or even inverted as observed during the 1998 Dead Sea earthquake (Bartal et al., 2000), suggests that parts of the seismic load travel along non-direct but faster 


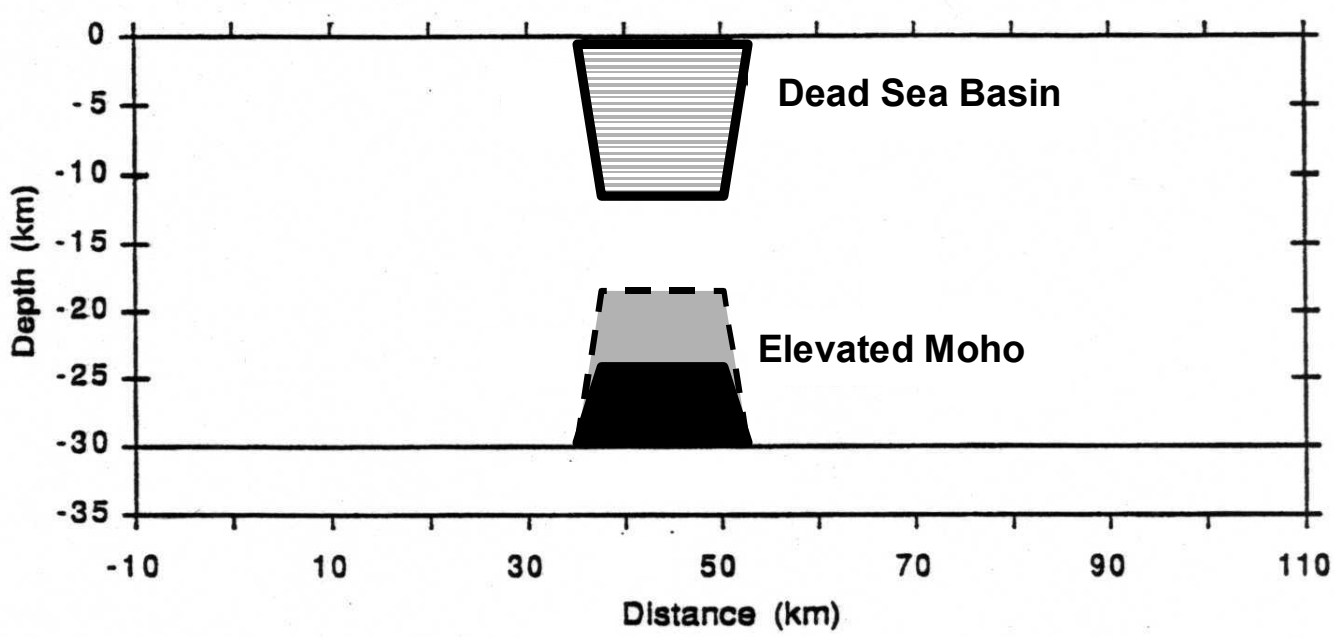

Fig. 4. E-W cross-section of the DSR substructure showing a deep sedimentary basin (hatched) and two models for an elevated Moho (modified after Ten Brink et al., 1993).

paths, possibly along the nearby DSR.

\section{The DSR substructure}

The results of several geophysical surveys carried out within the DSR area provide a model for its large-scale substructure that is in agreement with the present microseismicity pattern. This model also accounts for the aforementioned observations and suggests that it can influence the dissipation of seismic energy.

\subsection{Geometry and rheology within the DSR substructure}

The DSR substructure corresponds to the southern section of the Dead Sea Transform that extends $1000 \mathrm{~km}$ from the zone of plate divergence along the Red Sea to the TaurusZagros zone of plate convergence (Garfunkel, 1997). The DSR fault zone comprises a series of pull-apart basins of various sizes and depths (Ben-Avraham, 1997; Ben-Avraham et al., 1990; Ben-Avraham and Ten Brink, 1989; Garfunkel, 1981, 1997; Garfunkel and Ben-Avraham, 1996; Ten Brink and Ben-Avraham, 1989; Ten Brink et al., 1993). The Dead Sea Basin (DSB), one of the largest along the Dead Sea Transform (Garfunkel, 1997), has been studied in numerous geophysical surveys (Frieslander and Ben-Avraham, 1989; Frieslander et al., 1992; Ginzburg et Kashai, 1981; Ginzburg et al., 1981; Hall and Neev, 1978; Rotstein and Bartov, 1989; Ten Brink and Ben-Avraham, 1989; Ten Brink et al., 1993) whose results have been comprehensively analyzed by BenAvraham (1997). The DSB reaches $20 \mathrm{~km}$ in width and its length ranges between 140 to $200 \mathrm{~km}$ (Ten Brink et al., 1993). At its center, the DSB consists of a complex and undeformed sedimentary basin whose depth reaches 10 to $12 \mathrm{~km}$ (Larsen et al., 2002). A model for the DSB based on gravimetrical data (Ten Brink et al., 1993) shows strong con- trasts between the Northern and Southern sides of the basin that slope gently and gradually towards its center, and the Western and Eastern of the DSB that are controlled by subvertical N-S trending fault zones. At depth, this model predicts an elevated Moho at the base of the DSR substructure (Ten Brink et al., 1993; Fig. 4). In view of the fact that the elevated Moho can be found below the DSB at a depth ranging between 25 to $28 \mathrm{~km}$, the section of continental crust that lies below the DSB appears to be extremely thin, less than a dozen kilometers and possibly only $7-8 \mathrm{~km}$. This attenuated crustal section, comprising the two coalescing boundary fault zones, mark the boundary between the Arabian and the Sinai plates.

In terms of rheology, the clear geometrical boundaries of the DSB juxtapose lithologies that display a very high material contrast. The limestone or sandstone of the surrounding bedrock are in direct contact with the DSB, which contains a $10 \mathrm{~km}$ thick sedimentary fill of Neogene to Quaternary sediments (Garfunkel, 1997) that show no evidence of internal deformation that is not related to salt diapirism (Larsen et al., 2002). Most of the deformation of the DSR fault zone is accommodated along a series of boundary faults that mark the rheological jump between the rather ductile sediments of the DSB and the stiffer, brittle, bedrock. It is expected that this material contrast attenuates at depth as a function of increasing lithostatic pressure.

\subsection{Microseismicity}

Since the anisotropic progression of seismic sources is a function of their location in relation to material inhomogeneities, the recent microseismicity needs to be analyzed. Its pattern within the DSR area (Ben-Menahem et al., 1976; Shapira, 1997; Shapira et al., 1993) conforms well to the models for the DSR substructure previously discussed. A good agreement exists between the epicentral locations of the 


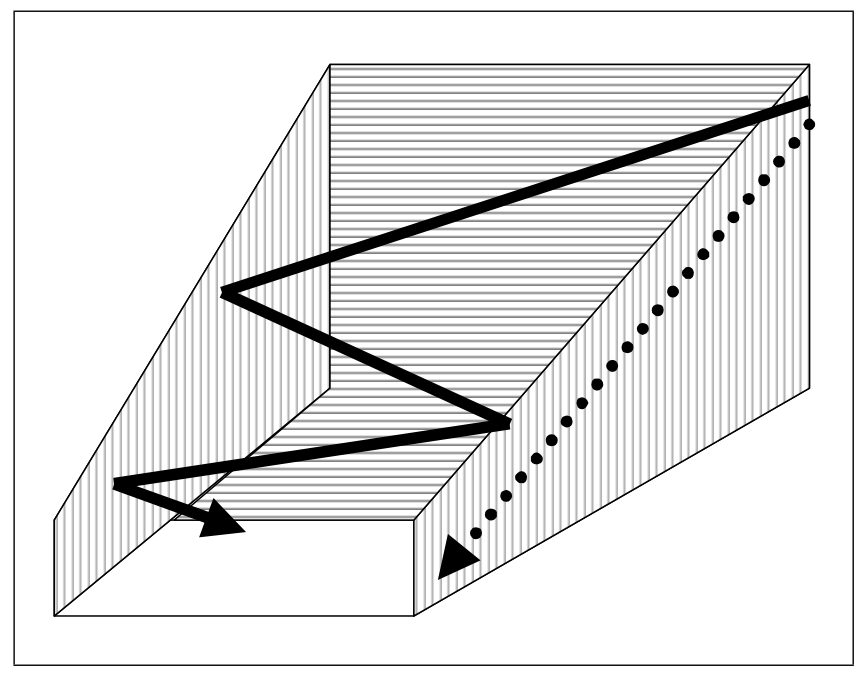

Fig. 5. Schematic seismic wave-guiding within the DSB for headwaves propagating along the boundary fault zone (dashed line) and for ray paths reflected by the DSB-boundary fault zone interface (solid line).

recent microseismicity and both mapped tectonic lineaments (Bartov, 1994, Garfunkel, 1997), and large-scale fault zones as revealed by E-W deep seismic survey (Rotstein and Bartov, 1989). Projected on tectonic maps (Bartov, 1994), the epicenters delineate the two sets of N-S trending boundary fault zones. In the Dead Sea area, the microseismic activity apparently observed directly above the undeformed sedimentary basin could have two sources. First, a number of events presently located within the DSB could, in fact, coincide with the boundary fault zones if the bias of event location (Bartal et al., 2000; Steinberg et al., 2001) due to travel time anomalies caused by the DSR is properly taken into consideration. Second, the origin of these epicenters could be a deeper area where both boundary fault zones coalesce under the DSB, provided the brittle-ductile transition zone extends deep enough.

In conclusion, it can be observed that the DSR substructure controls the microseismicity pattern in the region. Indeed, the large majority of sources are located along the deep boundary fault zones, where both material contrast and the stresses are maximal. From their initial sources, seismic loads then spread in an anisotropic way, either as headwaves along the material interface or reflected by the higher velocity bedrock, and are then trapped and guided within the DSR substructure in a way similar to signals propagating in an optic-fiber.

\section{Seismic Load Evolution}

The analysis of the seismic load evolution within the DSR substructure shows how it influences both path effects at a local and at a regional scale as well as site effects.

\subsection{Path effect}

At a local scale, the combination of a high material contrast and "bathtub"-like basin geometry provides for the strong guiding of seimic loads by the DSB substructure. According to Fermat's principle (Lay and Wallace, 1995), the higher seismic velocity of the surrounding bedrock provides for the confining of seismic loads within the DSB. Depending on their angle of incidence, the seismic loads that reach the material interface between the basin and the bedrock, at or beyond the critical angle, will either propagate as headwaves along the fault zones or be reflected back into the basin (Fig. 5). It should be noted that since the amplitude of headwaves decreases faster than that of amplitude of body waves over distance, the former will arrive first but the bulk of the energy will bounce within the low-velocity substructure.

Horizontally, the two boundary fault zones control the evolution of seismic loads. Waves that are not refracted by the two N-S subvertical boundary fault zones will progress either southwards or northwards, bouncing between both boundary faults. Since the E-W bounding fault zones dip at much lower angles, the seismic loads that are not refracted will be deflected towards the shallower ends of the DSB.

Vertically, the seismic velocity increases as a function of depth and the seismic loads that are not refracted will be deflected upwards in the basin. Since the velocity profile does not vary laterally, the geometry of the ray path in the N-S or $\mathrm{E}-\mathrm{W}$ directions will be a function of the varying angles of the boundary fault zones.

When applied to real data, the predictions for wave path within the DSR substructure provide an answer to some singular observations. Van Eck (1988) analyzed the attenuation of coda waves in the Dead Sea region, using 13 low magnitude $(M<3)$ local events situated within the DSR. Since the seismic stations located within the DSR displayed lower $Q_{c}$ values than stations situated on the Western flank, it demonstrates that at short epicentral distances, wave paths confined exclusively to the sedimentary basin have a higher scattering than wave paths that comprise a section along the material interface of the boundary fault zones and within solid bedrock. Similarly, Bartal et al. (2000) noted that a weak event ( $M$ 2.7) located North of the Dead Sea, reached a tripartite microarray, located out of the DSR at an epicentral distance of $81.5 \mathrm{~km}$, faster than predicted if it had followed the shortest path. In both cases, seismic loads or at least some part of them see their propagation efficiency enhanced, guided by the DSR substructure, they arrive faster at the target than anticipated and with signal amplitude higher than expected.

At a regional scale, two types of wave-guiding processes are expected. In the N-S direction, seismic loads are channeled from one pull-apart basin to the other. Indeed, the 1999 Turkish earthquakes produced very clear and strong first arrivals on the Israeli Seismic Network (ISN) (Villagran, 2000, personal communication) that show that the DSR substructure has the potential to propagate seismic signals with minimal energy losses. Conversely, the presence of a zone of inefficient short-period $S_{n}$ and $L_{g}$ propagation in the Lev- 
ant Shear Zone (Rodgers at al., 1997) can explain why some stations of the ISN display a low sensitivity to signals coming from the East (Ben Horin, 2000, personal communication). Since there is no ocanic crust to explain this deviation from standard IASPEI travel times (Kennett, 1991), it suggests that in the E-W direction, the DSR substructure works as a band-pass filter (Fig. 3). It is expected that the 10-12 km deep and $10 \mathrm{~km}$ wide DSB would high-band pass the oncoming $L_{g}$. At depth, the elevated concave Moho that bends wavefronts towards the surface disturbs the regular propagation of $S_{n}$. Both at a regional and at a local scale, a systematic analysis of travel time anomalies around the DSR substructure is still needed to determine the exact geometrical extent of the existing wave-guiding and to quantify the resulting amplitude changes as well as the frequency shifts of the various seismic ray bundles.

\subsection{Site effects}

The peculiar structure of the DSR and the shallow section of its substructure provide a series of elements that are known to play an important role in site effects and might enhance the level of ground motion.

First, the composition of the upper layers of the DSB consists of unconsolidated and weak sedimentary units in addition to a shallow groundwater table. These are ideal conditions for liquefaction or for the formation of gravity waves that can be generated in sedimentary basins during large earthquakes (Lomnitz, 1994). Near the surface, lithologies rich in clays, marls and aragonite that have developed into seismites have shown their extreme sensitivity to seismic loads (Marco et Agnon, 1995; Marco et al., 1996). A similar sensitivity was reported for underwater sediments that failed (Niemi and Ben-Avraham, 1994, 1997). In addition, the strong ground motion amplification of soft soils recorded during the 1985 Mexico City earthquake (Singh et al., 1988), indicates that the types of soils encountered within the DSB could be responsible for ground accelerations higher than expected. Within the DSR area, this type of site effect might lead to over-estimating the magnitudes of paeloseisms when these are based on empirical relationships between the magnitude and fault rupture length or fault displacement (McCalpin, 1996).

Second, the important topographic relief observed on either shoulders of the DSR certainly accounts for topographic effects (Geli et al., 1988; Caillot and Bard, 1990; Zaslawski and Shapira, 1995). Zaslawski and Shapira (1998) showed that the topographical amplification in the frequency range $1.2-2.0 \mathrm{~Hz}$ varies between a factor 2 to 4 , depending on the orientation of the topographic relief relative to the seismic source. For these reasons, the topographic effects can be held responsible for the high level of structural failure observed on either side of the DSR shoulders, directly beyond the sub-vertical fault zones bounding the DSR substructure.

If there is no doubt that site and topographic effects will affect ground motion predictions of future earthquakes, these effects cannot be evoked to explain a series of unex- pected instrumental observations or the peculiar distribution of earthquake-triggered landslides, failure features of ancient structures and elevators.

\section{Discussion}

The analysis of various types of failure features caused either by ancient or by recent earthquakes in the DSR region (Levy et al., 2000; Marco et al., 2000; Niemi and Ben-Avraham, 1994, 1997; Nur and Ron, 1997; Wachs and Levitte, 1978, 1981; Wust-Bloch, 2000; Wust-Bloch and Wachs, 2000) has led to the work hypothesis that the particular substructure of the DSR guides seismic loads. The review of geophysical surveys carried out in the DSR area has shown that the geometry of the deep DSB (Ten Brink et al., 1993), together with the high rheological contrast between the bedrock and the sedimentary filling, can account for the aforementioned observations. In addition, the wave-guiding process corroborates anomalies revealed either by monitoring the local seismicity (Arieh et al., 1977; Shamir, 1996; Shapira et al., 1993; Shapira and Shamir, 1996) or through seismic experiments at a local and a regional scale (Bartal et al., 2000; Rodgers et al., 1997; van Eck, 1988). Note that most of these anomalies have been observed in situations for which aggravating factors (site effects, topographic effects, geomorphological features and soil type) or specific ray paths cannot be invoked. When compared to empirical attenuation relations (Fig. 3.), the values recorded in the region are anomalously larger than standard predictions.

The selective distribution pattern of archeological structures that either failed or did not fail in the Northern part of Israel as a result of earthquakes is unusual (Wust-Bloch, 2000) and can be used to test the predictions of the model. The combined effects of surface ruptures, near-field ground motion, site amplification and wave guiding, directly account for the intense level of destruction of ancient structures within the DSR and its direct surrounding. This contrasts sharply with the presence of ancient structures that are still intact today, one or two dozen kilometers away from the DSR fault zone. Since no particular anisotropic anomaly that could enhance the attenuation or selectively filter on-coming seismic loads is known to exist on either side of the DSR, the preservation of these structures apparently results from the wave-guiding by the DSR substructure. Further to the North, along the DSR axis, the level of preservation of archeological structures is equally high, indicating that the wave-guiding process is minimal. Since a transition in tectonic style, from a chain of opening pull-apart basins towards the South, to a series of splaying fault zones to the North, can be observed around the border area between Lebanon and Israel, it suggests that the DSR substructure also changes and that its associated wave-guiding characteristics do not extend further North. Conversely, seismic loads propagating from the North are affected as soon as they enter into the dominating DSR substructure. In addition, preliminary results of numerical simulation of wave propagation within a simplified DSB en- 
vironment confirms that the amplitudes of the seismic waves within the Rift decay at a much slower rate than suggested by attenuation relations for the area (Goetshammer et al., submitted).

After testing this concept of seismic wave-guiding by the DSR substructure, further research should be undertaken to refine the model and quantify it thoroughly. Specifically, available local seismic data (microseismicity, calibration shots, quarry blasts) must be systematically analyzed for bias resulting from phase picking, hypocentral location or the velocity model used. If the station residual error remains significant, the station-receiver paths should be systematically investigated in relation to known tectonic features in order to locate anisotropic corridors or barriers and to predict seismic shadow zones. Finally, travel-time anomalies and modification of waveform characteristics need to be modeled at a local and at a regional scale. The results of these future quantitative investigations have implications for seismic monitoring such as that undertaken within the framework of the CTBT and for seismic hazard assessment in the region and possibly of other active rift regions. At a regional scale, wave-guiding can explain why some stations of the national seismic network display a low sensitivity to signals coming from the East. Inversely, the DSR has the potential to amplify and propagate the weakest seismic signals over unexpectedly large distances along its axis. At a local scale, the filtering of seismic signals by the DSR has meaningful implications since currently all reliance is placed on average attenuation curves for the region that do not take into consideration the specifics of the DSR substructure. This can undoubtedly lead to either mislocating microseismic sources or over-estimating the original source magnitude.

In terms of seismic hazard assessment, the wave-guide model raises a series of issues. Confining the seismic loads within a pipe-like structure reduces the surface area of the wave front, therefore resulting in energy levels higher than those of non-trapped propagation modes. In other words, the DSR substructure might be channeling large amounts of seismic energy with minimal energy losses along its $\mathrm{N}-\mathrm{S}$ axis and simultaneously minimizing the lateral spreading of the seismic load. Consequently, it might be reasonable to estimate the attenuation of a seismic load for a given site by considering its shortest path to the active DSR fault zone rather than by considering a whole range of potential epicentral distances. If experimentally verified, this process will certainly increase the known vulnerability of populations and structures within the DSR region. Additional modeling might also identify specific zones such as seismic focal points that can pose serious hazards to both humans as well as to the infrastructure. Special attention should be paid to the shallow extremities of the sedimentary basins that can focus ray bundles and function as a ramp as does a sand beach for the development of ocean surfs. At a very local scale, it was a similar process that triggered the buckling and failure of the upper deck of the Cypress Structure during the 17 October 1989 Loma Prieta earthquake (Lomnitz, 1994).
Acknowledgements. The author would like to thank Zvi BenAvraham and Manfred Joswig as well as two anonymous reviewers for comments and suggestions that greatly helped to improve the manuscript. I am extremely thankful to my wife Linda-Renée for her unconditional support and to our daughter Eliana for providing many sleepless but inspiring nights.

\section{References}

Amiran, D. H. K., Arieh, E., and Turcotte, T.: Earthquakes in Israel and adjacent areas: microseismic observations since 100 B.C.E., Isr. Exploration J., 44/3-4, 260-305, 1995.

Arieh, E., Peled, U., and Kafri, U.: The Jordan Valley earthquake of September 2, 1973, Israel J. Earth. Sci., 26, 112-118, 1977.

Bartal, Y., Villagran, M., Ben Horin, Y., Leonard, G., and Joswig, M. Definition of exclusion zones using seismic data, Pure \& Appl. Geophys., 158, 397-419, 2000.

Bartov, Y.: Seismicity and geological map of Israel and adjacent areas, Geological Survey of Israel and Institute for Petroleum Research, 1994.

Ben-Avraham, Z.: Geophysical framework of the Dead Sea: structure and tectonics, in: Niemi, T. M., Ben-Avraham, Z., and Gat, J. R. (Eds.): The Dead Sea; The Lake and its settings, Oxford Monographs on Geology and Geophysics, Oxford University Press, New York, 22-35, 1997.

Ben-Avraham, Z. and Ten Brink, U.: Transverse faults and segmentation of basins within the Dead Sea Rift, Journal of African Earth Sciences, 8, 603-616, 1989.

Ben-Avraham, Z., Ten Brink, U., and Charrach, J.: Transverse faults at the Northern end of the southern basin of the Dead Sea graben, Tectonophysics, 180, 37-47, 1990.

Ben-Menahem, A., Vered, M., and Nur, A.: Tectonics, seismicity and structure of the Afro-Eurasian junction, Physics of the Earth and Planetary Inter., 12, 1-50, 1976.

Caillot, V. and Bard, P.-Y.: Characterizing site effect for earthquake regulations in the French seismicity context: a statistical analysis, Proceedings of the LXth ECEE, Moscow, 4-B, 27-36, 1990.

Campbell, K. W.: Near source attenuation of paek horizontal acceleration, Bull. seism. Soc. Am., 71, 2039-2070, 1981.

Ellenblum, R., Marco, S., Agnon, A., Rockwell, T., and Boas, A.: Crusader castle torn apart by earthquake at dawn, 20 May 1202, Geology, 26-4, 303-306, 1998.

Frieslander, U. and Ben-Avraham, Z.: Magnetic field over the Dead Sea and vicinity, Marine and Petroleum Geology, 6, 148-160, 1989.

Frieslander, U., Rotstein, Y., and Bartov, Y.: High-resolution seismic survey in Elat, Geological Society of Israel, Annual Meeting, Ashquelon, p45, 1992.

Garfunkel, Z.: Internal structure of the Dead Sea leaky transform (rift) in relation to plate kinematics, Tectonophysics, 80, 81-108, 1981.

Garfunkel, Z.: The history and the formation of the Dead Sea basin, in: Niemi, T. M., Ben-Avraham, Z., and Gat, J. R. (Eds.): The Dead Sea; The Lake and its settings, Oxford Monographs on Geology and Geophysics, Oxford University Press, New York, 3656, 1997.

Garfunkel, Z. and Ben-Avraham, Z.: The structure of the Dead Sea basin, Tectonophysics, 266, 155-176, 1996.

Geli, L., Bard, P.-Y., and Julien, B.: The effect of topography on earthquake ground motion: a review and new results, Bull. seism. Soc. Am., 78, 42-63, 1988. 
Ginzburg, A. and Kashai, E.: Seismic measurements in the southern Dead Sea, Tectonophysics, 80, 67-80, 1981.

Ginzburg, A., Markis, J., Fuchs, K., and Prodehl, C.: The structure of the crust and upper mantel in the Dead Sea rift, Tectonophysics, 80, 109-119, 1981.

Gottschaemmer, E., Wenzel, F., Wust-Bloch, G. H., and BenAvraham, Z.: Earthquake modeling in the Dead Sea Basin, Geophysical Research Letter, 29, 12, 13 800-13 819, 2002.

Hall, J. K. and Neev, D.: Final report on the Dead Sea geophysical survey (July-August 1974), Marine Geology Division, Geological Survey of Israel, 1/78, 34p, 1978.

Joyner, W. and Boore, D.: Peak horizontal acceleration and velocity from strong motion records including records from the $1979 \mathrm{Im}$ perial Valley, California, earthquake, Bull. Seism. Soc. Am., 71, 2011-2038, 1981.

Keefer, D.: Landslides caused by earthquakes, Geol. Soc. Am. Bull., 95, 406-421, 1984.

Kennett, B. L. N. (Ed.): Seismological Tables. Research School of Earth Sciences, Australian National University, 167pp, 1991.

Larsen, B. D., Ben-Avraham, Z., and Shulman, H.: Fault and salt tectonics in the southern Dead Sea basin, Tectonophysics, 346, 71-90, 2002.

Lay, T. and Wallace, T. C.: Modern global seismology. Academic Press, New York, 521pp, 1995.

Levy, R., Rutenberg, A., Magnus, P., Marianchik, E., and Segal, F.: Performance of elevator systems in the 22 November 1995 Gulf of Eilat-Aqaba earthquake, Earthquake Spectra, 3, 607619,2000

Lomnitz, C.: Fundamentals of earthquake prediction, John Wiley \& Sons, New York, 326pp, 1994.

Marco, S. and Agnon, A.: Prehistoric earthquake deformation near Masada, Dead Sea graben, Geology, 23/8, 695-698, 1995.

Marco, S., Stein, M., and Agnon, A.: Long-term earthquake clustering: a 50000 year paleoseismic record in the Dead Sea graben, Journal of Geophysical Research, 101, 6179-6191, 1996.

Marco, S., Rockwell, T., Heimann, A., and Agnon, A.: Historical earthquake deformation revealed by $3 \mathrm{D}$ trenching on Dead Sea Transform. Proceedings of the Hokudan International Symposium on active faulting, January 17-26, Hokudan, Japan, 261263, 2000

McCalpin, J. P.: Paleoseismology, Academic Press, London, UK, 588pp, 1996.

Neimi, T. M. and Ben-Avraham, Z.: Evidence for Jericho earthquake from slumped sediments of the Jordan river delta in the Dead Sea, Geology, 22, 395-398, 1994.

Neimi, T. M. and Ben-Avraham, Z.: Active tectonics in the Dead Sea basin, in: Niemi, T. M., Ben-Avraham, Z., and Gat, J. R. (Eds.): The Dead Sea; The Lake and its settings, Oxford Monographs on Geology and Geophysics, Oxford University Press, New York, 73-81, 1997.

Nur, A. and Ron, H.: Armageddon's Earthquakes, International Geology Review, 39, 532-541, 1997.

Reiter, L.: Earthquake Hazard Analysis, Columbia University Press, New York, 254pp, 1990.

Rotstein, Y. and Bartov, Y.: Seismic reflection across a continental transform: an example from a convergent segment of the Dead Sea rift, Journal of Geophysical Research, 94/B3, 2902-2912, 1989.

Segal, F., Rutenberg, A., and Levy, R.: Earthquake response of structure-elevator system, Journal of Structural Engineering, ASCE, 122/6, 607-616, 1996.

Shamir, G.: The November 22, 1995, Nuweiba earthquake, Gulf of Elat (Aqaba): mechanical analysis, Geophysical Institute of Israel, 550/87/96 (114), 33pp, 1996.

Shapira, A.: On the seismicity of the Dead Sea basin, in: Niemi, T. M., Ben-Avraham, Z., and Gat, J. R. (Eds.): The Dead Sea; The Lake and its settings, Oxford Monographs on Geology and Geophysics, Oxford University Press, New York, 73-81, 1997.

Shapira, A. and Shamir, G.: The Gulf of Elat Earthquake of November 22th 1995, Preliminary report, GII, Seismological Division, January 1996, (in Hebrew), 5pp, 1996.

Shapira, A., Avni, R., and Nur, A.: A new estimate for the epicenter of the Jericho earthquake of 11 July 1927, Israel Journal of Earth Sciences, 42, 93-96, 1993.

Singh, S. K., Lermo, J., Dominguez, T., Ordaz, M., Espinoza, J. M., Mena, E., and Quaas, R.: The Mexico City earthquake of September 19, 1985 - A study of of amplification of seismic waves in the valley of Mexico with respect to a hill zone site, Earthquake Spectra, 4, 653-674, 1985.

Steinberg, D., Bodor, M., Bartal, Y., Ben Horin, Y., and Leonard, G.: Modeling errors, bias and error regions in IMS seismic monitoring of Israel, Physics of the Earth and Planetary Interiors, 123, 267-281, 2001.

Stern, E., Lewinson-Gilboa, A., and Aviram, J.: The new encyclopedia of archeological excavations in the Holy Land, The Israel Exploration Society, Carta, Jerusalem, 4 vol., 1552p, 1993.

Ten Brink, U. and Ben-Avraham, Z.: The anatomy of a pull-apart basin: seismic reflection observations of the Dead Sea, Tectonics, 8/2, 333-350, 1989.

Ten Brink, U., Ben-Avraham, Z., Bell, R. E., Hassouneh, M., Coleman, D. F., Andreasen, G., Tibor, G., and Coakley, B.: Structure of the Dead Sea pull-apart basin from gravimetry analyses, Journal of Geophysical Research, 98, 21 877-21 894, 1993.

van Eck, T.: Attenuation of coda waves in the Dead Sea region, Bull. Seism. Soc. Am., 78-2, 770-779, 1988.

Vered, M. and Streim, H. L.: A microseismic study of the July 11, 1927 Earthquake, Report IA-LD-1-107, Israel Atomic Energy Commission, Licensing Division, 21pp, 1976a.

Vered, M. and Streim, H. L.: The Safed Earthquake of 1.1.1837 and its implications on seismic risk evaluations in Israel, Report IA-LD-1-105, Israel Atomic Energy Commission, Licensing Division, 38pp, 1976b.

Vered, M. and Streim, H. L.: A microseismic study and the implications of structural damage of two recent major earthquake in the Jordan rift, Bull. Seism. Soc. Am., 67, 1607-1613, 1977.

Wachs, D. and Levitte, D.: Damage caused by landslides during the earthquake of 1837 and 1927 in the Galilee region, Geological Survey of Israel, Tech. Rep. H/5/78, 13pp, 1978.

Wachs, D. and Levitte, D.: Landslides in the Galilee, Geological Survey of Israel, Tech. Rep. H/1/80, 18pp, 1980.

Wachs, D. and Levitte, D.: Earthquake-induced landslides in the Galilee, Israel Journal of Earth Sciences, 30, 39-43, 1981.

Wachs, D. and Levitte, D.: Earthquakes in Jerusalem and the Mount of Olives landslide, Israel-Land and Nature, 9/3, 118-121, 1984.

Wachs, D. and Wust, G. H.: The effect of rainfall on landslide triggering in Northern Israel: an example of slope instability in an active seismic environment, European Geophysical Society, Annales Geophysicae, 16-IV, p. C-1178, 1998.

Wiseman, G., Hayati, G., Frydman, S., Aisenstein, B., David, D., and Flexer, A.: A study of a landslide in the Galilee, Israel, Israel Institute of Technology, Faculty of Civil Engineering, Haifa, 146, 1-12, 1970.

Wust, H. and Wachs, D.: Slope instabilities and the influence of seismicity: on-site investigations in Northern Israel, Geological 
Survey of Israel, Current Research, 10, 133-137, 1996.

Wust, G. H. and Wachs, D.: Monitoring aseismic slope activity in Northern Israel: a key to the comprehensive assessment of the seismic triggering of landslides, European Geophysical Society, Annales Geophysicae, 16-IV, p C-1201, 1998a.

Wust, G. H. and Wachs, D.: Integrating earthquake triggered landslides in catalogues of paleoseismic events: and essential but delicate task, European Seismological Commission, Annales Geophysicae, 23rd General Assembly, Tel Aviv, Israel, p24, 1998b.

Wust-Bloch, G. H. and Wachs, D.: Seismic triggering of unstable slopes in Northern Israel, Israel. J. Earth. Sci., 49, 103-109, 2000.

Wust, G. H., Wachs, D., and Michaeli, L.: Slope instability monitor- ing in the Gush Halav Area, Northern Israel, Geological Survey of Israel, Current Research., 11, 103-107, 1997.

Wust-Bloch, G. H.: Patterns of seismic energy dissipation within an active rift system: analysis of earthquake induced failure features in the Dead Sea Fault area, European Geophysical Society, 1st Stephan Mueller Conference, Tel Aviv, p38, 2000.

Zaslawski, Y. and Shapira, A.: Site response evaluations of three component seismic stations in Israel, Geophysical Institute of Israel, D18/159/94, pp23, 1995.

Zaslawski, Y. and Shapira, A.: The influence of topographical effects on seismic ground motion, XXVI General Assembly of the European Seismological Commission, Tel Aviv, Israel, August 23-28, Papers Vol., 241-245, 1998. 